\title{
Human-Centered Design for Development
}

\author{
Hendrik Knoche, EPFL IC LDM, Switzerland \\ PR Sheshagiri Rao, CK Trust, India \\ Jeffrey Huang, EPFL IC LDM, Switzerland
}

\begin{abstract}
This paper describes the challenges faced in ICTD by reviewing the lessons learned from a project geared at improving the livelihood of marginal farmers in India through wireless sensor networks. Insufficient user participation, lack of attention to user needs, and a primary focus on technology in the design process led to unconvinced target users who were not interested in the new technology. The authors discuss benefits that ICTD can reap from incorporating human-centered design (HCD) principles such as holistic user involvement and prototypes to get buy-in from target users and foster support from other stakeholders and NGOs. The study's findings suggest that HCD artifacts can act as boundary objects for the different internal and external actors in development projects.
\end{abstract}

Keywords: $\quad$ Case Study, Human-Centered Design (HCD), ICTD, ICT4D, M4D, Mobile HCI, Mobile Phones, WSN

\section{INTRODUCTION}

Rain-fed farming provides the bulk of the world's food supply and has tremendous potential to increase its productivity to meet the 2015 hunger reduction target of the Millenium Development Goal (MDG) (Trisorio-Liuzzi \& Hamdy, 2008). Changes and innovations are needed in land, water and crop management but the efforts required achieving this need to focus on increasing human and institutional capacity, build knowledge and improve management and infrastructure (Trisorio-Liuzzi \& Hamdy, 2008). These changes should also improve the

DOI: $10.4018 /$ jmhci.2011070101 livelihoods of rainfed farmers' who have not participated in the economic booms of the last two decades. How will farmers adopt innovations and which role can ICT play in this?

With the mobile phone as ready-at-hand platform a number of commercial agricultural information services have been recently launched but it is unclear whether these services will be adopted and whether they will foster further adoption of innovations in land, water and crop management. Decision support systems (DSS) that can help farmers make decisions on the poorly understood complex interactions of soil moisture, seeds, fertilizers and pesticides. Crop-soil simulation model based DSS have not seen much uptake by farmers in 
developed countries (Stephens \& Middleton, 2002) let alone developed countries (Matthews $\&$ Stephens, 2002). They seem a poor fit for the problems that farmers need to solve (Stone \& Hochman, 2004). However, most reports point to the absence of user involvement in the different stages of designing these services, which calls for research and development guided by human-centered design. Wireless sensor networks (WSN) that could help reduce the effort required to gather environmental data from the field to feed DSS are slowly maturing but have so far not proven their usefulness in this context. This makes the adoption of DSS in agriculture by resource-poor farmers in developing countries a challenge on various levels.

ICTD efforts that are part of a development projects have many goals. Funding organizations demand measurable results such as sustainability, i.e. continued benefits to the target population after the projects end, to better justify allocation of funds. The scope is typically much larger than in HCI studies or in HCD. Uptake and continued use is usually outside the scope of these research areas and left to industrial players. The same goes for standard desirable development outcomes such as local empowerment and capacity building along with policy implementation. Involving target users in participatory workshops or design activities represents another challenge as scientists do not have the trust of the rural population and trusted intermediaries such as NGOs can be skeptical whether engaging in joint activities with the researchers is worthwhile. We will present the lessons learned from the case study of an ICTD project, which aimed at improving the livelihood of resource-poor farmers but failed to interest them. The follow-up project relies on an HCD approach and focuses on getting buy-in from target users through iterative prototyping of applications. This will enable the farmers to envision using novel agricultural services on affordable mobile phones and in longitudinal studies they will be able to experience the value of these services themselves.

In the following section we provide background on innovation diffusion with a focus on agricultural contexts, the modes of farmer involvement in research, a wave of novel agricultural information services and the up-to-now disappointing adoption of DSS in agricultural contexts. Section 3 reviews the approach taken in an ICTD project developing a WSN-based DSS and describes the problems encountered. We then discuss the value of user evaluation of early prototypes and the use of mock-ups, storyboards, human subject consent forms and other HCD artifacts as boundary objects that provide can convince stakeholders, NGOs and other actors and present some wider ranging conclusions for ICT4D. The outlook section presents our revised approach to the second phase of the project.

\section{BACKGROUND}

Rain-fed farming produced the bulk of the world's food and generated $62 \%$ of the world's staple food (FAO, 2005). In 2009 agriculture employed over 240 million people in India $52 \%$ of the workforce (CIA, 2009) - many on small landholdings. In the province of Karnataka the size of the farms of $87 \%$ of farming families was less than four hectares (Barker \& Molle, 2004). The share of these small farms accounts for $50 \%$ of the total cultivated area, that of marginal farmers (less than one hectare) $39 \%$. Marginal farmers in India have profited comparatively little from the economic boom and poverty reduction of the last two decades (Basu \& Srivastava, 2005). This is mainly due to their reliance on rain, which is uncertain and occurs with great variance. However, the main gains in agricultural productivity lie in rain-fed farming and therefore solutions are sought as to how help bring these about.

Below we present how agricultural development through the extension model was a large success partly due to its reliance on an established trust relationship with farmers. Trust is time consuming to establish and many projects rely on established and trusted intermediaries such as NGOs or on the long-time involvement of researchers (Bentley, 1994). We present how 
the modes of farmer participation in research process are varied and the scope of participatory approaches is wider in development studies than in HCD. The section finishes with an overview of current agricultural ICTD initiatives and the dismal adoption of agricultural decision support systems due, to a large extent, to poor user involvement.

\section{Development}

Diffusion of agricultural innovations has a long tradition that predates HCI research by half a century. The US introduced extension services in 1914 to "relay useful and practical information on subjects relating to agriculture and home economics" and has been encouraging people to apply it. The success of the US model of agricultural extension and its innovationdevelopment process was largely attributed to the fact that $50 \%$ of the funding was targeted at diffusion activities. The local-level extension agents not only brought innovations tested by research universities to the farmers but also gathered feedback and tried to understand their needs. This information was fed back to the agricultural agency, thereby fostering organizational learning and change. For example, the initial focus on increasing production was extended to include farmers' information and entertainment needs. In spite of mass media proliferation a ratio of one extension worker to 100 farmers was maintained and, according to Rogers, much of the uptake of innovations could be attributed to the trust relationship they had with the farmers.

In terms of farmers' inclusion in the research process Biggs classified four modes of participation: contractual, consultative, collaborative and collegiate (Biggs, 1989). In the contractual mode the farmer's involvement is similar to that of a paid participant in a typical HCI study. The farmer acts and gets remunerated as a service provider of land, resources or services to the research project. The consultative mode follows a doctor-patient relationship in which the researchers try to elicit problems and suggest possible solutions to the farmer. In the collaborative mode the role of the farmers is more emancipated as they engage in continuous collaborations with the researchers as partners in the research process. This goes beyond typical user involvement in participatory designs in which participants rarely have ownership of the object of research and its insights and therefore obtain no direct benefit from the on-going research. In the collegial mode the researchers actively encourage the farmers to pursue research and development in rural areas.

In development parlance the activities carried out within the timeframe of the project produce outputs which ideally should result in outcomes in the mid-term (after the project has ended) and have long-lasting impact such as structural changes (Swiss Agency for Development and Cooperation SDC, 2008). During the 1980s, participatory approaches such as participatory rural appraisal (PRA) became popular with donors and organization active in the development domain as a response to the ineffectiveness of externally imposed, top-down, expert-oriented approaches (Cooke \& Kothari, 2001). Research in development distinguishes between efficiency and empowerment arguments as justifications for the use of participatory approaches. For the former, participatory approaches represent a tool to achieve better project outcomes - identical to their purpose in HCD - whereas the latter views participation as a process that increases the capacities of participants from marginal groups to improve their livelihoods (Cleaver, 1999), which is outside the scope of HCD. Among development scholars, there are calls for a critical review of the benefits and limits of participatory approaches based on the limitations of its methods and tools and its theoretical, political and conceptual limitations (Cooke \& Kothari, 2001).

\section{ICTD}

Agrowing number of information services have been recently trialed or launched to satisfy the information needs of farmers in India: aAqua mini (Bahuman \& Kirthi, 2007), mKrishi 
(Horvath, 2008), Reuters Market Light (RML) (Mehra, 2007), IFFCO Kisan Sanchar (Awasthi, 2008), and Nokia's Life Tools (Nokia Siemens Networks, Nokia and Commonwealth Telecommunications Organization (CTO), 2008) and CERES (Anurag, Vivek, \& Sasank, 2008) - see Rao and Sonar (2009) for a detailed comparison of these services. The provisioning of market prices for crops and agricultural inputs and the availability of the latter is a focus of many of these services. So far, research has found that the provisioning of market prices and news through mobile devices is of little interest to the farmers (Blattman, Jensen, \& Roman, 2003; Bahuman \& Ramamritham, 2010). Advice for the prevention, diagnosis and control of pests and diseases features high in farmers' needs but is not easy to implement in an automated way. Current services such as mKrishi and aAqua are human expert based and might not scale well to large numbers of users. Agrocom's (2008) real-time disease alert service through local weather stations in farmers' orchards proved financially unsustainable due to the high cost of the weather stations.

A number of ICTD projects have aimed at improving rural communication and knowledge building through solutions for illiterate users, e.g. audio wikis (Kotkar, Thies, \& Amarasinghe, 2008), discussion forums that extend existing mass media coverage such as community radios (Patel, Chittamuru, Jain, Dave, \& Parikh, 2010), and spoken web interfaces for user generated content (Kumar, Agarwal, \& Manwani, 2010). Information uptake can benefit from the fact that speech can provide proof of relevance and trustworthiness of the information; for example, if the voice is that of a known expert (Patel et al., 2010) or is attributed expert status by a trusted entity (Sherwani et al., 2009).

\section{Decision Support Systems in Agriculture}

For a number of crop varieties, agricultural research has come up with simulation models that can be harnessed to predict growth and yield. Their accuracy depends on the availability of environmental parameters such as, e.g. soil type, soil moisture and temperature, ideally over the lifetime of the crop. Crop simulation models have been used in some agricultural decision support systems (DSS) but this research community was largely unfamiliar with diffusion theory and participatory methods commonly found in HCI and HCD research. Reviews of decision support systems in agriculture in general (Cox, 1996; Newman, Lynch, \& Plummer, 2000) and in particular in development contexts (Stephens \& Middleton, 2002) read like textbook motivations for human centered design. Poor adoption abounds and, according to authors unfamiliar with HCD, is linked to unclear target users, non-inclusion of end-users prior or during development, mismatches between solution and end-users problems, poor user interfaces, users' distrust in the technology, lack of field testing, and insufficient training and support. Most DSS evolved from research tools and assumed very different tasks than those a farmer faces.

\section{COMMON SENSE NET FOR DSS}

The initial project set out in 2004 to improve marginal farmers' livelihoods in India through wireless sensor networks (WSN). Project partners included two technical experts (one in India and one in Switzerland), who were working in the field of WSN, an atmospheric research institute, and a local NGO in Chennakeshava Pura, which is a small village in the Karnataka province. Draughts there are common and rain-fed farmers are faced with uncertainty about their harvest yield each year due to inconsistent and unpredictable rainfall and crop pests and diseases.

A wireless sensor network (WSN) consists of a set of nodes, also called motes. Each mote contains sensors and a radio component to communicate with other motes in a networked multihop fashion. This allows for timely delivery of information and has demonstrated its value in a range of environmental monitoring contexts 
such as forest fires and avalanche detection. Commercial WSN solutions exist for home and building automation. In an agricultural context WSNs can be used to collect data relevant to plant physiology e.g., soil moisture and ambient temperature. Fed into crop simulation models the WSN data along with the weather forecast can be turned into forecasts of crop yield and help improve water management. With Moore's law as a guiding light its proponents deem it only a matter of time until prices of WSN equipment become cheap enough such that marginal farmers in developing countries will be able to be supported by WSN deployments in conjunction with crop, pest and disease simulation models.

Within the project the technical setup in the field included two WSN clusters. The collected data from each cluster of battery-driven motes was forwarded first through a base station node, which consisted of a single board computer (SBC) connected to the power grid and an uninterrupted power source (UPS). The SBC acted as a gateway from the cluster through its wireless LAN access point to a local server in the village. The server in turn forwarded the data to a central server at the Indian research institute. This wireless LAN gateway approach was abandoned due to connectivity problems. It was replaced by a GPRS based gateway as the mobile phone network in the area improved. From then on the base station forwarded the data directly to the central server.

\section{Methods and Approach}

The project started with a series of parallel activities: reviews on appropriate sensor board solutions, sensors for environmental monitoring and crop models. In collaboration with another research institute, the local NGO gathered general information needs on farming and livestock management in the following manner. First Rao et al. (2004) identified the livelihood activities of the rural community through a survey of each neighborhood or caste group in the village. The survey included all members of the community since the researchers deemed that the introduction of a new technology might affect all of them. People took part in group meetings and focus groups, according to their major livelihood activities, e.g., rain-fed farming, irrigated farming and shepherding. The group meetings centered on the information needs of participants' livelihood activities and the participants identified problems and prioritized them by consensus resulting in a ranked list of information needs. Subsequently, between three to six interested individuals from each livelihood group participated in a focus group hosted in the home of one of them to provide details about each identified problem in two to four hour facilitated discussions. High school teachers were then instructed to follow the same approach in 14 other localities. The information needs in the community were diverse and demonstrated that environmental data could be valuable to the farmers. Due to later disputes about ownership the user needs data was not further analyzed and remains unpublished.

Although further user involvement in the project was mainly contractual, no formal contract was established nor was remuneration offered. However, the prospect of a better future through the technology was deemed enough of an incentive for the farmers to:

1. Protect the hardware if it was put into their plot for testing purposes;

2. Report on the conditions in the field; and

3. Provide feedback on the value of the technology.

Technical research on WSN components and software was coupled with trials of casings that could be deployed in the field and withstand the climatic conditions. The main problems perceived by the researchers were due to the deployment of the hardware in the field. Energy was by far the biggest constraint. The lifetime of the WSN motes powered with two 3.6V lithium Ion batteries was typically in the range of weeks with a $5 \%$ duty cycle due to the synchronization overhead between the nodes (from wake-up to full operation) and networking protocol overhead. Excessive heat in the casings, which were exposed to sunlight 
and lacked cooling, reduced battery lifetime. The SBC required uninterrupted power for reception and forwarding of data, which was a challenge due to frequent power cuts and the limited duration covered by the UPS. The reliability of hardware was another concern; there was frequent/occasional malfunctioning and failure of node hardware due to unknown causes, lightning strikes and theft. This created the need for theft and dead motes detection algorithms.

The deployment of soil moisture probes proved difficult in the dry compacted soil. The soil around probes that were placed in a dug hole and covered afterwards was not representative of the rest of the field. The untouched compacted soil resulted in much higher run-off during rains than the soil in which a probe resided. Under very dry conditions the soil moisture probes often got detached from the enclosing soil and provided erroneous data.

Non-cooperating farmers who did not allow the placement of motes on their plots for propagation purposes required longer range radio connections. Radio wave propagation changed during the year for example due to crops growth and required higher margins during deployment.

Overall, the wealth of technological problems encountered did not leave room for understanding the needs of the marginal farmers and how the overall system could be designed in order to support those best in their decisionmaking processes. Perhaps the most interesting question - how the collected data would be presented to the prospective users - was left unaddressed. One notable exception was a controlled lab experiment geared at assisting novices in deploying a WSN. The metaphor of radio reception was employed for people to gauge signal strength and connectivity of motes in a hands- and eyes-free way when deploying the motes (Costanza et al., 2010). However, the participants in the study were technical students in Switzerland rather than farmers and extension workers in India.

During a local festivity one of the technical researchers gave a presentation to an unmoved community about the value of the research and the project's vision of the future for agriculture with WSN. This was not the only occasion on which it became clear that the target users were not interested in the technology, which they had experienced only through the presence of grey boxes installed by technical personnel in some fields. Informal discussions with marginal farmers revealed that they were not interested in any technology that did not bring them direct benefit in terms of rain, a perennial bore well, a road to the village, or monetary advantages e.g. through loans or subsidies (H. Jamadagni, private communication, 2007). Another researcher noted that "access to marginal farmers is not easy as they are very cautious; also, there is a significant danger in raising their expectations when approaching them. "Arepresentative from the local NGO explained that marginal farmers:

1. Generally felt left behind in the existing innovation processes;

2. Felt they furthered the careers of the scientists more than the scientists helped them improve their livelihoods;

3. Did not understand the scientific agricultural jargon used by the personnel deploying and maintaining the WSN (e.g. soil moisture and evapotranspiration); and

4. Felt uncertain about the cost-benefit ratio of the WSN technology.

According to the representative, in order for the farmers to adopt an innovation the benefits of the innovation have to be clearly demonstrated and be substantial. Marginal farmers in the area would not consider improvement in harvest in the range of $30 \%$ given the uncertainty, risk and assumed added cost and effort. It should be noted that the marginal farmers never experienced any interaction with the data from the WSN.

The project then refocused on scientists as the target user. A web-based application that allowed for monitoring environmental variables was developed and deployed. Each participating scientist completed a survey prior to a two-week test run. Data logging showed that only six of the thirty participants had used the system. The 
researchers were asked to identify possible use cases for WSN in the context of agriculture in individual debrief interviews. The four use cases that emerged focused on soil science, entomology, crop physiology and water management.

\section{DISCUSSION}

Since the inception of the original project wireless sensor networks hardware has not seen the expected price drops common in mass produced computer hardware. Because WSN currently represents a niche product economies of scale might still render them cheaper once they become more popular and mass-produced. An even bigger impediment to the WSN approach was the unavailability of power for the required infrastructural backbone to forward data to storage centers or off-site servers and the dismal battery life in the motes.

The project was confronted with theft of sensor nodes and very little interest on the farmers' part. Theft could partly be attributed to the fact that one of the participating farmers was quite rich but overall the lack of communication with the local population about what the technology was achieving and how the community would benefit from it seemed to be the main problem. Local outreach activities that improve people's livelihoods in the area where the research is conducted would have been one way to secure benevolent attitudes from the population about the research activities.

The bigger cultural differences appeared to be between technology savvy scientists and rural farmers than between technical partners from different cultures (India and Switzerland). One of the values of HCD lies in getting buy-in from the farmers by letting them experience potential benefits through interaction with early prototypes or envision them through mock-ups. If the benefits of an innovation cannot be reaped in the near future participatory approaches at least need to provide the participants and other facilitators such as NGOs with value for their time and involvement. In the context of sensor data made available to citizens and community groups for environmental activism Aoki et al. (2009) reported similarly disenfranchised opinions on the involvement of researchers developing new instruments or conducting studies from concerned citizens, environmental activists, employees of governmental regulatory agencies and environmental action organizations: “... researchers $[\ldots]$ who were perceived as promising a great deal, requiring significant effort to educate and support, and ultimately delivering nothing of relevance." This problem is systemic in part because of the relatively short project durations of ICT projects in comparison to the slow process through which technology adoption occurs and community groups foster societal change.

Despite extensive research on the topic of adoption and diffusion of innovations (Rogers, 1995), many ICTD projects devote most of their attention to research activities unrelated to diffusion. For adoption that involves risk trust lies at the heart of adoption. Few if any development projects can rely on an organizational infrastructure and locally trusted diffusion agents that made agricultural extension such a big success in the US, especially when the time frames for these funded activities are short. NGOs have become popular partners to provide access to participants in research studies since they often have earned the trust of locals due to their long-term commitment and proven interest in the community. The introduction and maintenance of commercial services for rural populations face the same challenges. The Reuters Market Light service, for example, was introduced and partly maintained by the local post office network (Mehra, 2007). An entrepreneurial approach through the introduction of product or services is one approach to making development projects sustainable. But due to a lack of incentives researchers in the ICT domain are often uninterested in investing time and effort in the entrepreneurial side or diffusion activities.

Human subjects' approval and consent forms - often dreaded as a bureaucratic burden by researchers in HCI - might help to put the 
involvement of farmers on solid footing and serve as basic guidelines for technical personnel unfamiliar with user based research. Participant consent forms, along with the description of standard protocols for interaction with participants, could be seen as boundary objects that provides different angles of understanding for partners from diverse scientific backgrounds.

\section{REVISED APPROACH: COMMON SENSE NET 2.0}

For the follow-up project the focus shifted to the development of an application that would directly benefit the farmers; thus, a different approach was devised. The consortium was restructured to include an HCI partner working in collaboration with a technical implementation partner and an agricultural expert working on the design and implementation of the application, while the NGO provides access to the local community and serves as a village base for participatory design activities, pilot and field tests.

\section{Technology}

The mobile phone provides the only feasible information platform when dealing with unreliable availability of electricity. It is one of the biggest successes in rural ICT development- the poster child of a sustainable technology. The cell towers are independent of the energy grid and ordinary mobile phone use is possible with available windows of opportunity for recharging the battery. Most importantly, many mobile phone models serve as programmable platforms.

To circumvent the power constraints we are integrating off-the-shelf components to create a low power sensor box, which continuously collects and stores data on soil moisture, humidity, soil temperature, ambient temperature and atmospheric pressure in the farmer's field. The farmer uses a mobile phone application to retrieve the sensor data from this field diary via low-power communication protocols, e.g. Bluetooth. The phone can transfer this information along with manually entered parameters about, e.g. the crop being farmed, on what soil, and the sowing date, to a server via the GSM network. This removes the need for inter-mote communication

\section{Applications}

The target application(s) running on mobile phones should be able to convey the following information and procedural knowledge to potentially illiterate but numerate users:

a) Farming strategies (such as choice of crops, choice of mono and multiple crops), price, expected yields and risk scenarios based on predictions by the weather board, see (Knoche et al., 2010);

b) A schedule for farming practices;

c) Crop simulation model based predictions of worst, average, and best case yields in financial terms;

d) Probabilities of and control strategies for pest and disease incidences for crops;

e) Guidelines for harvesting;

f) Economic aspects of water management of existing bore well use or procurement of water in relation to c); and

g) Local water levels and their fluctuations in bore wells.

For example, the crop simulation model takes the data sent to the server along with weather forecast information and computes yield scenarios (in $\mathrm{kg} /$ hectare) that are easy to understand for the farmer, e.g. best, worst and most probable case. Further effects on the yield if fertilizers and pesticides were applied or if more water could be supplied to the crop, are also included. Depending on the farmer's literacy rate the scenarios could be forwarded to the mobile phone through text messages (SMS), multimedia messages (MMS) or voice mail. Another option to produce the spoken word content is a phone based text-to-speech application. Any of these approaches will allow the farmer to repeatedly review and ponder the scenarios during his decision-making process. For this to come through, however, the system 
has to be designed such that the potentially illiterate farmers with little technical background can perform the following user interactions: pairing the sensor box with the mobile phone, installing and calibrating the sensor box, entering data manually, retrieving data from the sensor box, receive and reviewing outcome scenarios, re-installating the sensor box on a different plot, and understanding when and how to change the batteries in the sensor box (Knoche et al., 2010).

As a first step towards these applications, we have developed first mobile application prototypes, which allow for easy distribution of information through SMS. We are using the open source software FrontlineSMS (Banks \& Hersman, 2009) to provide members of the local NGO with an interface to disseminate and collect information transparently via SMS. Users can enter data through mobile phones forms that arrive via SMS at the FrontlineSMS server application. The data is kept in a database, which a script can automatically query for newly arrived messages and disseminate them through SMS GupShup - an Indian SMS gateway - to eligible receivers. Currently the technical work focuses on providing support on mobile phones for Kannada, the script and language spoken in the province of Karnataka, India. To support illiterate people the application requires a text-to-speech component as well as support for rendering the script. Our planned research on illiterate user interfaces will extend the existing research on mobile accessibility such as (Lalji \& Good, 2008).

Although WSN might not currently be viable as a technology in rural India, we have started using it for scientific research that will benefit rain-fed farmers. We are using the motes developed for the first project for research on agro-forestry, specifically to understand which trees and shrubs to plant to improve the stability of bunds and trenches for soil and rain water conservation in a given soil composition given and soil moisture content profile. Bunds and trenches represent one of the most viable and promising water management strategies but the effort to build these is substantial and farmers might need to see the benefits before they invest in them.

\section{Method}

The current project follows an HCD approach adapted to the development arena. Field trips have been undertaken to better understand the context and conditions under which the farmers live. These included visits to the next bigger town in which the farmers sell their goods, buy their inputs and implements, obtain credit, and access government and agricultural extension services and health care. Most importantly, a great deal of attention is given to how to involve the target users in participatory design activities and longitudinal tests. The farmers will be remunerated to participate in interviews, focus groups and design workshops and hopefully will recognize the benefits of participating in a longitudinal field study that provides new services.

The information needs of the rain-fed farmers have been revisited as has the trust they place in a range of information sources including their peers in the same location, similar farmers in different locations, government extension agents, inputs retailers, researchers and new findings from participatory research. Our work aims at furthering the understanding of the larger context - the ecosystem in which the farmer acts and makes his decisions based on available information both sensed and via other means. How can other actors and stakeholders make use of this information and trust it? Currently, the rain-fed farmers place almost no trust in information provided by scientific sources; they prefer information provided by local or regional peers even though these might have no sound basis in reality, e.g. in the case of weather forecasting.

Through initial interviews with rain-fed farmers and extension workers we will try to understand how they currently obtain the relevant information for the above topics and which role mobile phones play in their daily activities. After having understood whether the farmers themselves or extension workers will 
be the primary users of the application we will create personas, usage scenarios and storyboards to communicate the user requirements to the development team and to help in the iterative design process with the farmers. In participatory design sessions we will try to elicit suitable ways to convey the desired information to the target users and find appropriate interaction designs. We will then conduct a longitudinal field study in which participants can use a working prototype system in real life over the course of six months during a cropping season.

We will use a bootstrapping approach, which will provide participants in a longitudinal field test with a growing set of information services that are not necessarily related to sensor or agricultural data. One of the first ways to provide a tangible benefit to participating farmers could be day labor opportunities, availability of government programs and weather forecasts on their mobile phones. In the spirit of action research the project will support a member of the local NGO to provide this information to the local population throughout one year. We aim to make this service self-sufficient through an advertising supported or subscription payment model. This entrepreneurial approach could provide the foundation for continued provision of benefits to the local community and possibly grow to encompass other adjacent communities. Another incentive for the NGO is that they can use this mobile phone based group communication tool for other purposes in the future.

As a part of this strategy we are planning to rope in further actors and stakeholders that could use the data from the sensors and entered by farmers for other purposes. Local agricultural offices and extension agents should be able to better serve their community if they knew more about which crops are currently planted, what fertilizers might be in demand, and which pest and diseases are rampant and have a means to convey information about remedies, subsidies and their programs to them. Retailers of agricultural inputs and their wholesalers might improve their supply chains if more information on potential local demand were available. The sensor driven field diary could be used in the determination of rain insurance claims. Proving eligibility of claims has been problematic since the available rainfall data has been too coarse in its granularity. Shepherds or goat herders whom farmers have to pay for grazing on their land to naturally fertilize it could use the field diary to estimate the risk of parasites on the plot with an appropriate application. This information would have high value due to the high cost for parasite treatments. The farmers could learn more from each other if the information about their farming strategies and approaches and resulting yield was shared amongst them. HCD artifacts such as scenarios, storyboards and prototypes of any kind can help in communicating with these target groups. Especially prototypes that help envision actual use and its benefits can help in getting buy-in from them and keep discussions with them focused on concrete and achievable goals. Furthermore, they increase the conveyed credibility and determination on part of the researcher and that the interaction with him is worthwhile.

One of the problems encountered with the HCD approach in a project of this kind is the upfront time required to understand the contexts of use, the target user and which information they need in the context of use and through what kind of interface. Technical partners unfamiliar with the modus operandi and value of HCD and under pressure having to deliver the front- and back-end solutions may be eager to start with their own vision of what needs to be built without fully understanding what will be required.

\section{CONCLUSION}

The cost-benefit of ICT solutions and participation in research projects need to be clearly communicated to potential target users. This was particularly problematic during the first phase of this project during which farmer involvement was contractual but involved no remuneration. It also did not provide any opportunity for farmers to envision the use of the 
technology or experience benefits first hand as no user interface was ever made available. Lo-fi prototyping and other participatory techniques that are standard in the tool set of HCD provide many opportunities to envision use of technology and get a glimpse of potential benefits. Both prototyping artifacts and consent forms can act as boundary objects that help scientists from different backgrounds to design better ICT solutions. Especially working prototypes that include user interfaces can fill this role and help convince NGOs, stakeholders and other external actors of the value of the project and that it will actually deliver on its visions.

On a more strategic level the HCI community needs to further raise funding organizations' awareness of the value of HCD in delivering research that addresses the needs of people in ICTD projects. The iterative approach of HCD also makes for a good transparent way to monitor progress and therefore aid in project evaluations. In order to not fall short on the expectations created the HCD community should look into potential shortcomings of participatory approaches in the larger scope in the development domain.

\section{REFERENCES}

Agrocom. (2008). Agrocom software technologies privatelimited-achievements. Retrieved from http:// agrocom.co.in/achievements.php

Anurag, P., Vivek, B., \& Sasank, T. (2008). CERESinformation services. Retrieved from http://ceres.co.in

Aoki, P. M., Honicky, R. J., Mainwaring, A., Myers, C., Paulos, E., Subramanian, S., \& Woodruff, A. (2009). A vehicle for research: Using street sweepers to explore the landscape of environmental community action. In Proceedings of the 27th International Conference on Human Factors in Computing Systems (pp. 375-384).

Awasthi, U. (2008). IFFCO Kisan Sanchar Ltd. Retrieved from http://www.iffco.nic.in/applications/ iffcowebr5.nsf/?Open

Bahuman, A., \& Kirthi, R. (2007). aAqua mini. Retrieved from www.agrocom.co.in
Bahuman, A., \& Ramamritham, K. (2010). aAQUA mobile - almost all questions answered. Retrieved from http://www.slideshare.net/bahuman/aaquamobile-pilot-to-advise-50000-farmers-over-thetelephone

Banks, K., \& Hersman, E. (2009). FrontlineSMS and ushahidi - a demo. In Proceedings of the $3 \mathrm{rd}$ International Conference on Information and Communication Technologies and Development, Doha, Qatar (pp. 484-484).

Barker, R., \& Molle, F. (2004). Evolution ofirrigation in South and Southeast Asia. Colombo, Sri Lanka: Comprehensive Assessment Secretariat.

Basu, P., \& Srivastava, P. (2005). Scaling-up microfinance for India's rural poor. Washington, DC: World Bank. doi:10.1596/1813-9450-3646

Bentley, J. W. (1994). Facts, fantasies, and failures of farmer participatory research. Agriculture and Human Values, 11(2), 140-150. doi:10.1007/ BF01530454

Biggs, S. D. (1989). Resource-poor farmer participation in research: A synthesis of experiences from nine national agricultural research systems. OFCOR Comparative Study Paper, 3, 1-4.

Blattman, C., Jensen, R., \& Roman, R. (2003). Assessing the need and potential of community networking for development in rural India. The Information Society, 19(5), 349-364. doi:10.1080/714044683

CIA. (2009). The world factbook. Retrieved from https://www.cia.gov/library/publications/the-worldfactbook/geos/in.html

Cleaver, F. (1999). Paradoxes of participation: Questioning participatory approaches to development. Journal of International Development, 11(4), 597-612. doi:10.1002/(SICI)10991328(199906)11:4<597::AID-JID610>3.0.CO;2-Q

Cooke, B., \& Kothari, U. (2001). Participation: The new tyranny? London, UK: Zed Books.

Costanza, E., Panchard, J., Zufferey, G., Nembrini, J., Freudiger, J., Huang, J., et al. (2010). SensorTune: A mobile auditory interface for DIY wireless sensor networks. In Proceedings of the 28th International Conference on Human Factors in Computing Systems, Atlanta, GA. (pp. 2317-2326).

FAO. (2005). Database. Retrieved from http:// faostat.fao.org/

Horvath, R. (2008). Innovation - mobile services. In Proceedings of the CII/GIS Conference. 
Knoche, H., Prabhakar, T., Jamadagni, H., Pittet, A., Sheshagiri Rao, P., et al. (2010). Common sense net 2.0 - minimizing uncertainty of rain-fed farmers in semi-arid India with sensor networks. In UNESCO Technologies for Development. Lausanne, Switzerland.

Kotkar, P., Thies, W., \& Amarasinghe, S. (2008). An audio wiki for publishing user-generated content in the developing world. In Proceedings of the HCI Workshop for Community and International Development, Florence, Italy.

Kumar, A., Agarwal, S. K., \& Manwani, P. (2010). The spoken web application framework: User generated content and service creation through low-end mobiles. In Proceedings of the International Cross Disciplinary Conference on Web Accessibility, Raleigh, NC (pp. 1-10).

Lalji, Z., \& Good, J. (2008). Designing new technologies for illiterate populations: A study in mobile phone interface design. Interacting with Computers, 20(6), 574-586. doi:10.1016/j.intcom.2008.09.002

Matthews, R. B., \& Stephens, W. (2002). Cropsoil simulation models: Applications in developing countries. New York, NY: CABI. doi:10.1079/9780851995632.0000

Mehra,A. (2007). Reuters market light now available in local post offices across Maharastra. Retrieved from http://news.thomasnet.com/companystory/ Reuters-Market-Light-Now-Available-in-LocalPost-Offices-across-Maharashtra-808401

Nokia Siemens Networks, Nokia and Commonwealth Telecommunications Organization (CTO). (2008). Towards effective e-governance: The delivery of public services through local e-content. Retrieved from http://www.e-agriculture.org/en/news/towardseffective-e-governance-delivery-public-servicesthrough-local-e-content
Patel, N., Chittamuru, D., Jain,A., Dave, P., \& Parikh, T. S. (2010). Avaaj Otalo - a field study of an interactive voice forum for small farmers in rural India. In Proceedings of the 28th International Conference on Human Factors in computing systems, Atlanta, GA (pp. 733-742).

Rao, K. V., \& Sonar, R. M. (2009). M4D applications in agriculture: Some developments and perspectives in India. Defining the ' $D$ ' in ICT4D, 104-111.

Rao, S., Gadgil, M., Krishnapura, R., Krishna, A., Gangadhar, M., \& Gadgil, S. (2004). Information needs for farming and livestock management in semi-arid tracts of Southern India (Tech. Rep. No. $A S$ 2). Bangalore, India: CAOS.

Rogers, E. M. (1995). Diffusion of innovations (4th ed.). New York, NY: Free Press.

Sherwani, J., Palijo, S., Mirza, S., Ahmed, T., Ali, N., \& Rosenfeld, R. (2009). Speech vs. touch-tone: Telephony interfaces for information access by low literate users. In Proceedings of the IEEE/ ACM International Conference on Information and Communication Technologies and Development (pp. 447-457).

Stephens, W., \& Middleton, T. (2002). Why has the uptake of decision support systems been so poor. Crop-Soil Simulation Models, 129-147.

Stone, P., \& Hochman, Z. (2004). If interactive decision support systems are the answer, have we been asking the right questions? In Proceedings of the 4th International Crop Science Congress on New Directions for a Diverse Planet, Brisbane, Australia.

Swiss Agency for Development and Cooperation SDC. (2008). Annual report 2008 Switzerland's international cooperation. Retrieved from http://www. cosude.ch/de/Home/Dokumentation/ressources/ resource_en_181617.pdf

Trisorio-Liuzzi, G., \& Hamdy, A. (2008). Rain-fed agriculture improvement: Water management is the key challenge. Paper presented at the 13th IWRA World Water Congress, Montpellier, France. 
Hendrik Knoche is a post-doctoral researcher in the Media x Design Laboratory at EPFL. He has worked worked on interaction design and user experience both on desktop and mobile devices for the last ten years in industry and academia. He holds a Diploma in computer science from the University of Hamburg and pursued his PhD in computer science in Angela Sasse's Human Centered Systems Group at University College London. Prior to his PhD studies he worked with David Kirsh at the Interactive Cognition Lab of UC San Diego on an ONR funded project on distributed collaboration. He has worked on European projects on interactive TV centric services and mobile TV and various user studies relating to mobile social networking, automated content adaptation, biometric systems, video quality and visual experience. His research interests include socio-technical systems, human-centered design, HCI and mediated experiences.

P. R. Sheshagiri Rao is a Farmer \& Researcher, residing in a semi arid village in South India. For research he has worked with Indian Institute of Science, Bangalore (through its field station located in his farm) for over twenty years in areas of - Natural resource management, Biodiversity, Agro-ecology, adaptation to Climate variability \& change and application of ICT. He has co-authored a book on Biodiversity and conservation policy and published in peer reviewed journals in each of his areas of research interest and served as member of several Regional and National policy making bodies. In recent years, his applied research work has led to consultancy assignments with- Earth Institute, Columbia University; Corporate firms and NGOs. He leads a small NGO, CK Trust, and several community based natural resource management efforts. He has academic training in both Agriculture and Ecology with a Masters degree in Plant breeding and Genetics from University of Agricultural sciences, Bangalore.

Jeffrey Huang is the Director of the Media x Design Laboratory and a Full Professor in Architecture and Information Systems at EPFL, with joint appointments at the Faculty of Computer and Communication Sciences, and the Faculty of Architecture, Civil and Environmental Engineering. His research explores the convergence of physical and virtual environments. Current research projects include the integration of computing into architecture and cities, novel processes of design (parametric design, algorithmic design), mobile applications, and more generally, design-centered approaches to human-computer interaction. Prior to EPFL, Huang was a faculty member at Harvard's Graduate School of Design. Huang received his DiplArch from the ETHZ, and his Masters and Doctoral Degrees from Harvard University, where he was awarded the Gerald McCue medal. 